\title{
Lowering serum urate does not improve endothelial function in patients with type 2 diabetes
}

\author{
W. S. Waring • J. A. McKnight • D. J. Webb • \\ S. R. J. Maxwell
}

Received: 4 May 2006 / Accepted: 3 August 2007 / Published online: 10 October 2007

(C) Springer-Verlag 2007

\begin{abstract}
Aims/hypothesis Endothelial dysfunction contributes to excess cardiovascular risk in patients with type 2 diabetes. There is strong evidence of an association between high serum uric acid concentrations and endothelial dysfunction, and uric acid has been proposed as an independent cardiovascular risk factor in type 2 diabetes. We hypothesised that lowering of uric acid concentrations might allow restoration of endothelial function in this high-risk group. Methods Intravenous urate oxidase $(1.5 \mathrm{mg})$ was administered to ten patients with type 2 diabetes and ten healthy participants in a two-way, randomised, placebo-controlled, crossover study. Forearm blood flow responses to intrabrachial acetylcholine, sodium nitroprusside and $N^{\mathrm{G}}$-monomethyl-L-arginine (L-NMMA) were measured using venous occlusion plethysmography. The augmentation index (AIx) was determined by pulse wave analysis as a measure of large arterial stiffness.

Results Acetylcholine and L-NMMA evoked lesser responses in patients with type 2 diabetes than in healthy participants. Baseline AIx was higher in patients with type 2 diabetes (mean \pm SD: $13.1 \pm 6.9 \%$ ) than in healthy participants $(2.0 \pm 5.1 \% ; p=0.006)$. Urate oxidase lowered serum
\end{abstract}

W. S. Waring · D. J. Webb · S. R. J. Maxwell

Clinical Pharmacology Unit, University of Edinburgh,

Edinburgh, UK

J. A. McKnight

Department of Diabetes, Western General Hospital,

Edinburgh, UK

\section{W. S. Waring $(\bowtie)$}

The Queen's Medical Research Institute, University of Edinburgh,

3rd Floor East, Room E3.22, 47 Little France Crescent,

Edinburgh EH16 4TJ, UK

e-mail: s.waring@ed.ac.uk uric acid concentrations by $64 \pm 11 \%(p<0.001)$, but this had no effect on forearm blood flow responses or AIx in either group.

Conclusions/interpretation Substantial short-term lowering of uric acid did not have a direct vascular effect, suggesting that, on its own, this might not be an effective strategy for restoring endothelial function in patients with type 2 diabetes.

Keywords Antioxidants · Atherosclerosis .

Cardiovascular risk - Endothelial function - Hyperuricaemia . Nitric oxide · Type 2 diabetes · Urate oxidase · Uric acid ·

Vascular function

\begin{tabular}{ll}
\multicolumn{2}{l}{ Abbreviations } \\
AIx & augmentation index \\
L-NMMA & $N^{\mathrm{G}}$-monomethyl-L-arginine \\
NO & nitric oxide \\
SNP & sodium nitroprusside
\end{tabular}

\section{Introduction}

In health, the endothelium plays an important role in conserving vascular integrity, in part through the synthesis and release of vasoactive substances such as nitric oxide (NO) [1]. Endothelial dysfunction is believed to play a key role in the early development of atherosclerosis and precedes plaque development [2]. Experiments carried out in animal models of diabetes have shown impaired endothelium-dependent vasomotion [3]. Blood flow responses to endothelial NO-dependent vasodilators, for example acetylcholine, are characteristically impaired in patients with diabetes [4-6]. Importantly, endothelial dysfunction is an independent predictor of increased 
cardiovascular risk in patients with type 2 diabetes, hypertension and established atherosclerosis [7-9].

Vascular NO also serves to maintain large arterial compliance. Increased large arterial stiffness is found in conditions characterised by endothelial dysfunction, including type 2 diabetes [10]. Arterial stiffening causes more rapid pulse waveform reflection, which causes higher aortic systolic pressure and lower diastolic blood pressure. Haemodynamic alterations that increase left ventricular systolic load and reduce coronary perfusion pressure during diastole might contribute further to cardiovascular risk [11]. These findings have stimulated increased interest in large arterial stiffness and endothelial dysfunction as potential therapeutic targets for reducing cardiovascular risk. However, the exact mechanisms responsible for endothelial dysfunction in patients with type 2 diabetes remain unclear [12].

Epidemiological data indicate a strong correlation between serum uric acid concentrations and cardiovascular risk in unselected populations, while high concentrations predict the development of type 2 diabetes [13, 14]. Patients with type 2 diabetes have higher uric acid concentrations than healthy people, and there are strong associations between uric acid concentrations and the risk of coronary heart disease, stroke and cardiovascular mortality [15-18]. An inverse correlation exists between serum uric acid concentrations and endothelial function in high-risk populations [19]. Furthermore, high uric acid concentrations may contribute to endothelial dysfunction in patients with type 2 diabetes [20,21]. It is widely believed that the relationship between uric acid concentrations and vascular dysfunction is a passive association, such that high uric acid concentrations are simply a marker of upregulated xanthine oxidase activity [22]. Xanthine oxidase is an established source of oxygen radicals that are capable of scavenging $\mathrm{NO}$ and, therefore, diminishing NO-dependent vasodilator capacity. Upregulation of xanthine oxidase activity and accumulation of reactive oxygen species are believed to contribute to endothelial dysfunction in patients with type 2 diabetes [23].

In contrast, recent experimental observations suggest that high uric acid concentrations themselves might be capable of impairing endothelial function [24]. Uric acid is capable of evoking an inflammatory response [25], and peri-vascular inflammation has been suggested as a mechanism that might link high uric acid concentrations to vascular dysfunction in chronic heart failure [26]. In patients with hypertension, the association between high uric acid concentrations and endothelial dysfunction is independent of established major risk factors, C-reactive protein and insulin resistance, suggesting that uric acid might be capable of directly impairing vascular function via inflammation-independent pathways [27]. These observations have stimulated interest in lowering uric acid as a novel therapeutic strategy for reducing cardiovascular risk [28]. However, insufficient evidence is available to resolve whether high uric acid concentrations might be an independent causal risk factor or, alternatively, a passive risk marker. In order to establish whether uric acid might contribute causally to endothelial dysfunction, the present study adopted an approach that allows uric acid lowering without affecting xanthine oxidase activity.

The aim was to administer urate oxidase as a specific means of uric acid lowering and to examine the potential effects on endothelial function and large arterial stiffness in patients with type 2 diabetes. We hypothesised that high uric acid concentrations may impair vascular function in patients with type 2 diabetes and that lowering serum uric acid concentrations might restore endothelial function.

\section{Methods}

Participants The protocol was reviewed and approved by the local research ethics committee and the study conducted in accordance with the principles outlined in the Declaration of Helsinki. Written informed consent was obtained from all participants. Ten patients with type 2 diabetes were recruited from the Diabetes Outpatient Clinic at Western General Hospital (Edinburgh, UK) and ten age- and sex-matched individuals serving as controls were recruited from a community database of healthy participants held at the Clinical Research Centre (University of Edinburgh, Edinburgh, UK). The primary outcome measure was maximum forearm blood response during acetylcholine administration, expressed as a percentage change from baseline blood flow in the infused forearm. Assuming a standard deviation of $15 \%$ in both groups, it was calculated that completion by ten participants in each group, using a crossover design, would detect an absolute difference of $20 \%$ between treatment arms with $90 \%$ power at a two-sided $\alpha$-level of 0.05 . Inclusion criteria were men or women, aged 35-50 years, who met the American Diabetes Association classification for type 2 diabetes [29]. Patients were excluded if any of the following applied: overt cardiovascular, respiratory or renal disease; taking any regular medication (except anti-hyperglycaemic medication); blood pressure $>160 / 90 \mathrm{mmHg}$; serum creatinine $>100 \mu \mathrm{mol} / \mathrm{l}$; serum cholesterol $>6.0 \mathrm{mmol} / \mathrm{l}$; or regular tobacco use.

Drugs and reagents Urate oxidase (Rasburicase; SanofiSynthelabo, Paris, France) was reconstituted in $10 \mathrm{ml}$ sterile $0.9 \%$ saline solution (Baxter Healthcare, Thetford, UK) immediately before administration. Saline alone was used as placebo. Other drugs used were acetylcholine (CibaVisionOphthalmics, Southampton, UK), sodium nitroprusside (SNP; David Bull Laboratories, Warwick, UK), $N^{\mathrm{G}}$-monomethylL-arginine (L-NMMA; Calbiochem-Novobiochem, Notting- 
ham, UK) and lidocaine (1\% Xylocaine; AstraZeneca, Luton, UK).

Endothelial function The brachial artery of the non-dominant arm was cannulated with a 27-standard wire gauge steel needle (Cooper's Needle Works, Birmingham, UK), using local anaesthetic (1 ml subcutaneous lidocaine) and aseptic technique. Vasoactive drugs were administered via a 16-gauge epidural catheter (Portex, Hythe, UK) connected to a syringe pump (IVAC P1000; Alaris Medical, Basingstoke, UK). Intraarterial saline was infused for $30 \mathrm{~min}$ to establish baseline haemodynamic conditions, followed by administration of acetylcholine at a concentration of $7.5,15$ or $30 \mu \mathrm{g} / \mathrm{min}$, SNP at 2,4 or $8 \mu \mathrm{g} / \mathrm{min}$, and L-NMMA at 2 or $4 \mathrm{mmol} / \mathrm{min}$. The order of infusion of acetylcholine and SNP was randomised between participants and constant between visits. Each dose was administered for $6 \mathrm{~min}$, with saline infused for $20 \mathrm{~min}$ between drugs to allow restoration of basal blood flow. The rate of intra-arterial infusion was kept constant at $1 \mathrm{ml} / \mathrm{min}$ throughout. Blood flow was measured in both forearms by venous occlusion plethysmography using the Hokanson EC4 system (Bellevue, WA, USA) [30, 31]. Cuffs placed across both wrists were inflated to $200 \mathrm{mmHg}$ during measurement, to cut off the hand circulation, and cuffs placed across the upper arms were inflated intermittently to $40 \mathrm{mmHg}$ to occlude venous return from the forearm without impeding arterial inflow. By obstructing venous outflow, but not arterial inflow, the forearm volume initially increases in proportion to forearm blood flow. Mercury-in-silastic strain gauges were placed over the circumference of the upper forearm, as part of a Wheatstone bridge, to detect changes in forearm circumference and, thereby, evaluate forearm volume changes. The strain gauges were connected to a microcomputer and signals were recorded using Chart software (ADInstruments, Hastings, UK). Measurements were recorded during the last $3 \mathrm{~min}$ of each $6 \mathrm{~min}$ infusion, and the mean of the last five recordings was used to determine flow in each arm. Blood flow was expressed as the ratio between the infused and non-infused forearms, and responses to vasoactive drugs were expressed as percentage change from baseline.

Haemodynamic measurements Applanation tonometry (SPC-301 micromanometer; Millar Instruments, Houston, TX, USA) was used to assess arterial pressure waveforms at the dominant radial artery site; pulse wave analysis software (Sphygmocor; PWV Medical, Sydney, NSW, Australia) provided corresponding central pressure waveforms using a validated transfer function [32]. The augmentation index (AIx), which is a reproducible measure of large artery stiffness, was calculated as the difference between the second and first central systolic blood pressure peaks, expressed as a percentage of pulse pressure [33, 34]. Heart rate and blood pressure were recorded in the dominant arm using a validated oscillometric device (HEM-705CP; Omron, Kyoto, Japan) [35].

Biochemical assays A $5 \mathrm{ml}$ venous blood sample was collected in a serum gel tube (Sarstedt, Leicester, UK) before and $24 \mathrm{~h}$ after drug administration for serum uric acid measurement. Blood samples were centrifuged at $1000 \times g$ for $10 \mathrm{~min}$ at $4^{\circ} \mathrm{C}$, decanted immediately and serum then stored at $-40^{\circ} \mathrm{C}$ until assays were performed. Uric acid, glucose and electrolyte concentrations were determined simultaneously using an automated colorimetric assay (Vitros 950; Ortho-Clinical Diagnostics, Amersham, UK). The standard reference range for uric acid using this assay was 120 to $420 \mu \mathrm{mol} / \mathrm{l}$; intra-assay precision was $1.8 \%$.

Preliminary dose-finding To determine the optimal timing and dose of urate oxidase, a placebo-controlled single ascending dose-finding was performed in two healthy men aged 33 and 36 years. Each underwent systemic administration of urate oxidase $(0,0.375,0.75,1.125$ or $1.5 \mathrm{mg})$ during separate visits, which were at least 1 week apart; timing of placebo administration was randomly allocated. Venous blood was collected for uric acid measurement at baseline and at $0.25,0.5,0.75,1,2,4,12,24,48,72$ and $96 \mathrm{~h}$ after drug administration.

Protocol Participants were enrolled in a randomised, twoway, single-blind, placebo-controlled, crossover study with a 1 week washout period between visits. Investigations were performed in a quiet room maintained at 24 to $26^{\circ} \mathrm{C}$. An 18-standard gauge intravenous cannula was inserted into a suitable vein of the non-dominant antecubital fossa, using local anaesthetic and aseptic technique. Participants rested semi-supine for $20 \mathrm{~min}$ to establish baseline haemodynamic conditions, and underwent systemic administration of $1.5 \mathrm{mg}$ of urate oxidase or placebo over $1 \mathrm{~min}$. Haemodynamic variables were measured immediately predose and at $15 \mathrm{~min}$ intervals up to $60 \mathrm{~min}$ post-dose. Participants were then allowed to leave and asked to return the next day so that AIx and endothelial function could be assessed at $24 \mathrm{~h}$ after administration. Few data are available on urate oxidase pharmacokinetics or the time profile of its activity as an electron acceptor or on the removal of its catalytic products. After examining the available literature, we calculated that a $24 \mathrm{~h}$ washout period between administration of urate oxidase and measurement of cardiovascular variables would achieve substantial uric acid lowering while minimising the potential confounding effects of circulating enzyme [36, 37].

Data analysis and statistics Forearm blood flow responses were compared using two-factor ANOVA and post-hoc 
Table 1 Dose-finding data showing percentage fall in serum uric acid concentration after systemic urate oxidase administration

\begin{tabular}{|c|c|c|c|c|c|c|c|c|c|c|}
\hline \multirow{3}{*}{$\begin{array}{l}\text { Time post- } \\
\text { dose }(\mathrm{h})\end{array}$} & \multicolumn{10}{|c|}{ Dose of urate oxidase administered (mg) } \\
\hline & \multicolumn{2}{|l|}{0} & \multicolumn{2}{|l|}{0.375} & \multicolumn{2}{|l|}{0.75} & \multicolumn{2}{|l|}{1.125} & \multicolumn{2}{|l|}{1.5} \\
\hline & $\begin{array}{l}\text { Participant } \\
1\end{array}$ & $\begin{array}{l}\text { Participant } \\
2\end{array}$ & $\begin{array}{l}\text { Participant } \\
1\end{array}$ & $\begin{array}{l}\text { Participant } \\
2\end{array}$ & $\begin{array}{l}\text { Participant } \\
1\end{array}$ & $\begin{array}{l}\text { Participant } \\
2\end{array}$ & $\begin{array}{l}\text { Participant } \\
1\end{array}$ & $\begin{array}{l}\text { Participant } \\
2\end{array}$ & $\begin{array}{l}\text { Participant } \\
1\end{array}$ & $\begin{array}{l}\text { Participant } \\
2\end{array}$ \\
\hline 1 & -2 & -1 & 9 & 10 & 7 & 14 & 27 & 33 & 34 & 47 \\
\hline 2 & -2 & -4 & 9 & 10 & 5 & 15 & 20 & 26 & 41 & 45 \\
\hline 4 & 0 & -7 & 6 & 17 & 11 & 22 & 26 & 41 & 49 & 90 \\
\hline 12 & 0 & -4 & 2 & 9 & 6 & 29 & 9 & 70 & 70 & 88 \\
\hline 24 & 4 & -9 & 14 & 15 & 6 & 48 & 23 & 74 & 75 & 83 \\
\hline 48 & - & - & - & - & 1 & 10 & 10 & 48 & 64 & 68 \\
\hline 72 & - & - & - & - & - & - & -4 & 7 & 11 & 27 \\
\hline 96 & - & - & - & - & - & - & -2 & 3 & -2 & 8 \\
\hline
\end{tabular}

two-tailed Student's $t$ tests, where appropriate. Data from all volunteers were included in the ANOVA; factors considered were treatment arm and dose of vasoactive drug. Haemodynamic variables and uric acid concentrations were compared between groups by Welch-corrected Student's $t$ tests. The Mann-Whitney $U$ test was used to compare creatinine concentrations on the assumption that these would not be distributed normally. Statistical significance was accepted at a two-tailed 0.05 level in all cases. ANOVA for repeated measures was performed to take account of the stepwise increase in doses.

\section{Results}

Preliminary dose-finding study Urate oxidase caused a dose and time-dependent reduction in serum uric acid concentration, with the maximal fall in serum uric acid concentration occurring between 12 and $24 \mathrm{~h}$ after administration of $1.5 \mathrm{mg}$ of urate oxidase (Table 1). Therefore, a $1.5 \mathrm{mg}$ dose was selected for administration $24 \mathrm{~h}$ prior to cardiovascular assessments.

Baseline characteristics These are shown in Table 2. Patients with type 2 diabetes had a higher BMI, plasma glucose concentrations and serum uric acid concentrations than healthy volunteers. Blood pressure and serum cholesterol concentrations were well matched between groups. As expected, urate oxidase administration caused a similar and extensive reduction of serum uric acid concentrations across the whole study population (Table 3 ).

Baseline AIx values These were considerably higher in patients with type 2 diabetes than in healthy volunteers (Table 3). Neither urate oxidase nor placebo administration had any short-term effect on systemic haemodynamics in either group. Comparison by paired Student's $t$ tests revealed no significant difference in response to urate oxidase vs placebo for AIx $(p=0.678)$, heart rate $(p=0.735)$, systolic blood pressure $(p=0.840)$ and diastolic blood pressure $(p=$ 0.812 ) in patients with type 2 diabetes. Furthermore, AIx and haemodynamic variables were similar between pre-dose and $24 \mathrm{~h}$ post-dose values, despite substantially lowered serum uric acid concentrations (Table 3). Baseline blood flow

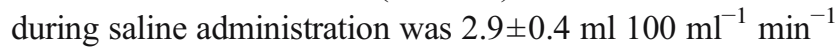

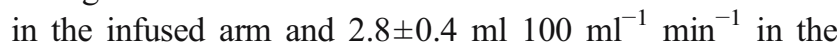

Table 2 Baseline characteristics of the study population

\begin{tabular}{|c|c|c|c|}
\hline Characteristic & $\begin{array}{l}\text { Healthy } \\
\text { group }\end{array}$ & $\begin{array}{l}\text { Type } 2 \\
\text { diabetes } \\
\text { group }\end{array}$ & $\begin{array}{l}p \\
\text { value }\end{array}$ \\
\hline Number (male) & $10(6)$ & $10(6)$ & - \\
\hline Age (years) & $43 \pm 4$ & $42 \pm 4$ & 0.829 \\
\hline Height (m) & $1.75 \pm 0.15$ & $1.76 \pm 0.13$ & 0.925 \\
\hline Weight $(\mathrm{kg})$ & $96 \pm 11$ & $114 \pm 28$ & 0.041 \\
\hline BMI $\left(\mathrm{kg} / \mathrm{m}^{2}\right)$ & $28.9 \pm 6.8$ & $36.7 \pm 8.9$ & 0.019 \\
\hline Heart rate (per min) & $71 \pm 9$ & $73 \pm 10$ & 0.675 \\
\hline $\begin{array}{l}\text { Systolic blood } \\
\text { pressure }(\mathrm{mmHg})\end{array}$ & $123 \pm 20$ & $124 \pm 23$ & 0.945 \\
\hline $\begin{array}{l}\text { Diastolic blood } \\
\text { pressure }(\mathrm{mmHg})\end{array}$ & $76 \pm 15$ & $75 \pm 14$ & 0.855 \\
\hline Serum creatinine $(\mu \mathrm{mol} / \mathrm{l})$ & $68(65-72)$ & $70(65-75)$ & 0.481 \\
\hline Serum cholesterol (mmol/l) & $4.1 \pm 1.0$ & $4.0 \pm 1.5$ & 0.873 \\
\hline $\begin{array}{l}\text { Total cholesterol: } \\
\text { HDL-cholesterol ratio }\end{array}$ & $4.4 \pm 2.0$ & $5.0 \pm 3.7$ & 0.637 \\
\hline $\begin{array}{l}\text { Serum triacylglycerol } \\
(\mathrm{mmol} / \mathrm{l})\end{array}$ & $1.5 \pm 0.9$ & $1.9 \pm 1.3$ & 0.452 \\
\hline Plasma glucose (mmol/l) & $4.1 \pm 1.3$ & $6.8 \pm 2.7$ & 0.008 \\
\hline $\mathrm{HbA}_{1 \mathrm{c}}(\%)$ & $5.8 \pm 2.7$ & $7.7 \pm 3.4$ & 0.096 \\
\hline Packed cell volume & $0.41 \pm 0.04$ & $0.39 \pm 0.05$ & 0.238 \\
\hline Serum urate $(\mu \mathrm{mol} / 1)$ & $268 \pm 38$ & $349 \pm 73$ & 0.010 \\
\hline
\end{tabular}

Values are means $\pm \mathrm{SD}$ or medians (interquartile range). The $p$ values are for the difference vs healthy participants by Welch-corrected $t$ tests and by the Mann-Whitney $U$ test for creatinine 
Table 3 Serum uric acid concentrations and haemodynamic variables associated with administration of 1.5 mg of urate oxidase or placebo

\begin{tabular}{|c|c|c|c|c|}
\hline & \multicolumn{2}{|c|}{ Healthy participants } & \multicolumn{2}{|c|}{ Patients with type 2 diabetes } \\
\hline & Placebo & Urate oxidase & Placebo & Urate oxidase \\
\hline \multicolumn{5}{|c|}{ Serum uric acid $(\mu \mathrm{mol} / \mathrm{l})$} \\
\hline Pre-dose & $272 \pm 26$ & $268 \pm 28$ & $344 \pm 57$ & $342 \pm 41$ \\
\hline $24 \mathrm{~h}$ & $249 \pm 31$ & $102 \pm 14^{\mathrm{a}}$ & $328 \pm 57$ & $118 \pm 39^{\mathrm{a}}$ \\
\hline Change at $24 \mathrm{~h}$ & $-22 \pm 30$ & $-166 \pm 34^{\mathrm{a}}$ & $-15 \pm 39$ & $-223 \pm 56^{\mathrm{a}}$ \\
\hline \multicolumn{5}{|l|}{ AIx $(\%)$} \\
\hline Pre-dose & $2.0 \pm 4.1$ & $1.8 \pm 3.6$ & $13.4 \pm 7.9$ & $12.6 \pm 6.7$ \\
\hline $24 \mathrm{~h}$ & $1.9 \pm 3.8$ & $2.1 \pm 3.1$ & $14.0 \pm 5.9$ & $14.5 \pm 5.9$ \\
\hline \multicolumn{5}{|c|}{ Heart rate (per min) } \\
\hline Pre-dose & $70 \pm 5$ & $72 \pm 6$ & $76 \pm 7$ & $71 \pm 6$ \\
\hline $0.5 \mathrm{~h}$ & $70 \pm 6$ & $71 \pm 7$ & $75 \pm 6$ & $71 \pm 6$ \\
\hline $1 \mathrm{~h}$ & $71 \pm 7$ & $70 \pm 6$ & $76 \pm 8$ & $71 \pm 6$ \\
\hline $24 \mathrm{~h}$ & $70 \pm 5$ & $71 \pm 8$ & $71 \pm 6$ & $71 \pm 6$ \\
\hline \multicolumn{5}{|c|}{ Systolic BP (mmHg) } \\
\hline Pre-dose & $123 \pm 11$ & $123 \pm 12$ & $124 \pm 12$ & $124 \pm 13$ \\
\hline $0.5 \mathrm{~h}$ & $124 \pm 12$ & $125 \pm 10$ & $120 \pm 13$ & $128 \pm 11$ \\
\hline $1 \mathrm{~h}$ & $122 \pm 13$ & $124 \pm 11$ & $120 \pm 13$ & $125 \pm 12$ \\
\hline $24 \mathrm{~h}$ & $123 \pm 12$ & $123 \pm 11$ & $122 \pm 10$ & $121 \pm 10$ \\
\hline \multicolumn{5}{|c|}{ Diastolic BP (mmHg) } \\
\hline Pre-dose & $76 \pm 6$ & $76 \pm 7$ & $76 \pm 7$ & $75 \pm 6$ \\
\hline $0.5 \mathrm{~h}$ & $75 \pm 8$ & $76 \pm 8$ & $74 \pm 5$ & $75 \pm 7$ \\
\hline $1 \mathrm{~h}$ & $76 \pm 7$ & $77 \pm 7$ & $75 \pm 5$ & $80 \pm 7$ \\
\hline $24 \mathrm{~h}$ & $77 \pm 7$ & $76 \pm 7$ & $76 \pm 4$ & $76 \pm 6$ \\
\hline
\end{tabular}

Values are means $\pm \mathrm{SD}$

a $p<0.001$ for difference from placebo by paired Student's $t$ tests

non-infused arm in healthy people and $2.6 \pm 0.5 \mathrm{ml} 100 \mathrm{ml}^{-1}$ $\min ^{-1}$ and $2.5 \pm 0.4 \mathrm{ml} 100 \mathrm{ml}^{-1} \mathrm{~min}^{-1}$ respectively in patients with diabetes. Forearm blood flow responses to acetylcholine were lower in patients with type 2 diabetes than in healthy people $(p=0.005$ by ANOVA; $p=0.031, p=0.029$ and $p=0.003$ by post-hoc Student's $t$ tests at increasing acetylcholine doses). Responses to L-NMMA were also lower in patients with type 2 diabetes than in healthy participants ( $p=0.005$ by ANOVA; $p=0.061$ and $p=0.001$ by post-hoc Student's $t$ tests at increasing L-NMMA doses). Responses to SNP were similar between both groups $(p=0.560)$. Administration of urate oxidase did not alter the blood flow responses to acetylcholine, SNP or L-NMMA (Fig. 1). No adverse events were encountered in any participant.

\section{Discussion}

Urate oxidase caused a time- and dose-dependent fall in circulating uric acid concentrations. The dose range studied was lower than in earlier Phase I research $(0.05-0.2 \mathrm{mg} / \mathrm{kg})$ [35]. It was important to establish the minimum effective dose in our study population, in order to minimise the potential confounding by direct drug effects on vascular function. The fall in serum uric acid concentrations evoked by urate oxidase was substantially greater than previously reported for other pharmacological means, such as allopurinol [20, 38]. Despite this, AIx and forearm blood flow responses to acetylcholine, SNP and L-NMMA were unaltered, indicating that uric acid lowering had no effect on large arterial stiffness or endothelial function.

Patients with type 2 diabetes had higher serum uric acid concentrations than the healthy group, as found in earlier studies [14]. Blood pressure and serum cholesterol concentrations were well matched between patients with type 2 diabetes and healthy participants. AIx was significantly higher in patients with diabetes, representing increased large arterial stiffness compared with non-diabetic individuals, as found in earlier studies [10]. Forearm blood flow responses to SNP were similar in both groups, indicating that endothelium-independent NO-mediated responses are preserved in patients with type 2 diabetes. However, responses to acetylcholine, an endothelium and NO synthase-dependent vasodilator, were impaired, consistent with the endothelial dysfunction found in this group. As expected, blood flow responses to L-NMMA were diminished, indicating that basal NO synthase activity is impaired in patients with type 2 diabetes. Substantial reduction of serum uric acid concentrations had no effect on large artery compliance or 
a

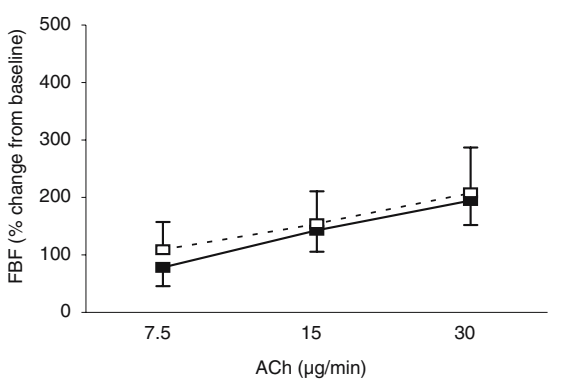

d

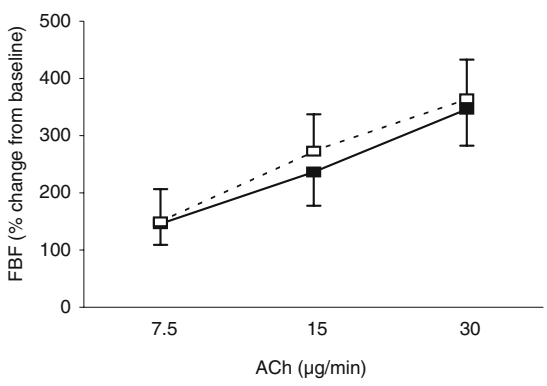

b

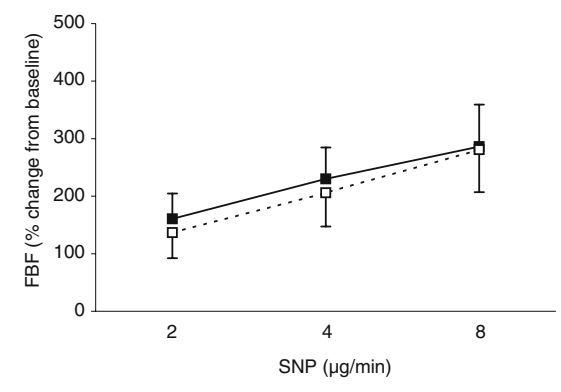

e

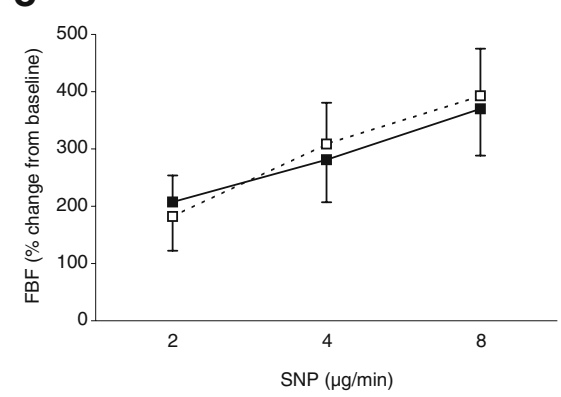

C

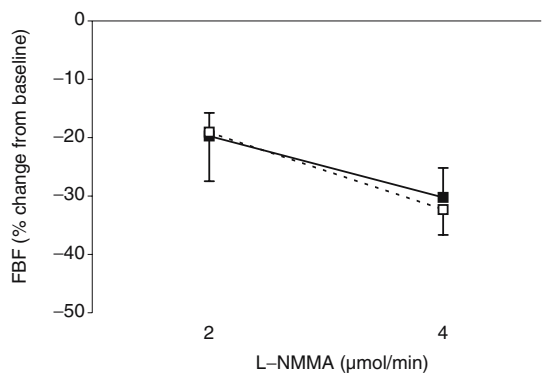

f

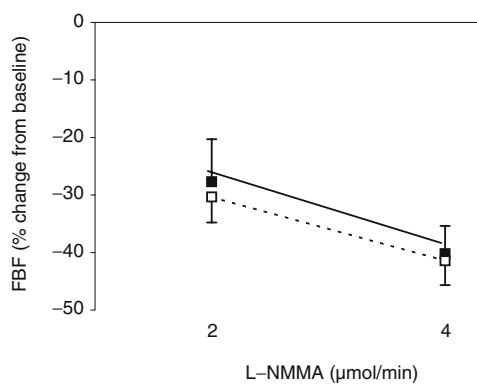

Fig. 1 a-c Forearm blood flow $(F B F)$ responses in patients with type 2 diabetes to intra-brachial acetylcholine $(A C h)(\mathbf{a})$, SNP (b) and LNMMA (c) as infused:non-infused FBF ratio, expressed as percentage change from baseline. $\mathbf{d}-\mathbf{f}$ FBF responses in healthy participants to intra-brachial ACh (d), SNP (e) and L-NMMA (f) as infused:non-

endothelium-dependent vasodilator responses. Despite the established relationship between high serum uric acid concentrations and endothelial dysfunction, lowering uric acid concentrations had no direct effect. In patients with type 2 diabetes, uric acid concentrations did not exert any discernible effects on NO-dependent endothelial function. In other high-risk patients, allopurinol allowed restoration of endothelial function, whereas probenicid had no effect, although both treatments lowered serum uric acid concentrations to the same extent [39]. These findings suggest that allopurinol is capable of restoring endothelial function by mechanisms other than uric acid lowering. Reducing uric acid concentrations alone is unlikely to be an effective strategy for improving endothelial function.

Xanthine oxidase contributes to oxidative stress and progression of vascular dysfunction in patients with type 2 diabetes [40]. Allopurinol is capable of lowering serum uric acid and allows restoration of endothelial function in patients with type 2 diabetes [20,21]. It inhibits endothelium-bound xanthine oxidase less intensely than circulating xanthine oxidase [41], suggesting that, in contrast to other work, the effects of allopurinol might be attributable to uric acid lowering. Allopurinol also possesses intrinsic antioxidant properties, which might exert independent effects on vascular function [42]. We selected urate oxidase in this study to avoid the confounding effects of allopurinol and to allow more substantial lowering of serum uric acid concen- infused FBF ratio expressed as percentage change from baseline. Results are shown as means $\pm \mathrm{SD}$ after administration of urate oxidase and placebo. Closed squares/continuous line, placebo; open squares/ dotted line, urate oxidase

trations [43, 44]. Despite this, urate oxidase itself is an electron acceptor. We attempted to minimise the possible effects of this by allowing a $24 \mathrm{~h}$ washout period between urate oxidase administration and assessment of endothelial function. Furthermore, xanthine oxidase itself is inhibited by uric acid at physiological concentrations $[45,46]$. Therefore, regardless of the means of uric acid lowering, a reciprocal increase in xanthine oxidase activity might occur and this might in part explain our findings.

Cardiovascular risk and development of atherosclerosis are likely to be influenced by chronic exposure to risk factors. A limitation of the present study is that only short-term measures of large arterial stiffness and endothelial function were examined. Nonetheless, endothelial function is a dynamic measure that is capable of responding rapidly to a variety of interventions, for example xanthine oxidase inhibition [47]. Despite this, endothelial dysfunction is characteristically found in the presence of any one of a number of major cardiovascular risk factors, including regular tobacco use, hypertension and hypercholesterolaemia, and is rapidly restored by their amelioration [48, 49]. There is a strong temporal relationship between the presence of major cardiovascular risk factors, endothelial dysfunction and development of atherosclerosis. Assessment of endothelial function as a risk marker appears valid because of correlations between short-term and long-term effects of interventions that are known to be effective in reducing 
cardiovascular risk, for example blood pressure lowering and statin therapy $[48,49]$. A potential confounder is that plasma glucose concentrations were higher in patients with type 2 diabetes than in healthy participants during cardiovascular investigations. Hyperglycaemia is a recognised cause of impaired endothelial function [50]. However, plasma glucose concentrations were less than $9.8 \mathrm{mmol} / \mathrm{l}$ and generally well controlled in patients, as evidenced by baseline $\mathrm{HbA}_{1 \mathrm{c}}$ concentrations. Furthermore, glucose concentrations were similar between study visits and, therefore, unlikely to have significantly influenced the lack of response to treatment. We were careful to exclude patients with concurrent illness or those taking medications that might have confounded effects on endothelial function. Our patient population is therefore not truly representative of type 2 diabetic patients encountered in the everyday clinical setting, thereby possibly limiting the generalisability of our findings. Serum uric acid concentrations in patients with type 2 diabetes although higher than those of healthy volunteers, fell within the upper part of the normal reference range. If baseline uric acid concentrations had been higher, then the study might have allowed an effect of urate oxidase administration to be discerned more readily.

To conclude, the present study shows that substantial reduction of serum uric acid concentrations does not restore vascular function in patients with type 2 diabetes. These findings suggest that high serum uric acid concentrations, as typically found in patients with type 2 diabetes, are not causally linked to endothelial dysfunction. These data do not support a mechanistic link between high uric acid concentrations and endothelial dysfunction, suggesting that the relationship is based on association rather than causation. Further research is required to examine the potential impact of reducing serum uric acid concentrations in other high-risk groups and to explore the possible long-term effects of uric acid lowering in patients with type 2 diabetes.

Acknowledgements W. S. Waring was supported by a BristolMyers-Squibb Cardiovascular Research Fellowship when this research was performed.

Duality of interest The authors declare that there is no duality of interest associated with this manuscript.

\section{References}

1. Albrecht EW, Stegeman CA, Heeringa P, Henning RH, van Goor H (2003) Protective role of endothelial nitric oxide synthase. J Pathol 199:8-17

2. Rabelink TJ, Luscher TF (2006) Endothelial nitric oxide synthase: host defense enzyme of the endothelium? Arterioscler Thromb Vasc Biol 26:267-271

3. Zhao G, Zhang X, Smith CJ et al (1999) Reduced coronary NO production in conscious dogs after the development of alloxaninduced diabetes. Am J Physiol 277:268-278
4. Pinkney JH, Downs L, Hopton M, Mackness MI, Bolton $\mathrm{CH}$ (1999) Endothelial dysfunction in Type 1 diabetes mellitus: relationship with LDL oxidation and the effects of vitamin E. Diabet Med 16:993-999

5. Guerci B, Kearney-Schwartz A, Bohme P, Zannad F, Drouin P (2001) Endothelial dysfunction and type 2 diabetes. Part 1: physiology and methods for exploring the endothelial function. Diabetes Metab 27:425-434

6. Makimattila S, Yki-Jarvinen H (2002) Endothelial dysfunction in human diabetes. Curr Diab Rep 2:26-36

7. Nitenberg A, Pham I, Antony I, Valensi P, Attali JR, Chemla D (2005) Cardiovascular outcome of patients with abnormal coronary vasomotion and normal coronary arteriography is worse in type 2 diabetes mellitus than in arterial hypertension: a 10 year follow-up study. Atherosclerosis 183:113-120

8. de Jager J, Dekker JM, Kooy A et al (2006) Endothelial dysfunction and low-grade inflammation explain much of the excess cardiovascular mortality in individuals with type 2 diabetes. The Hoorn Study. Arterioscler Thromb Vasc Biol 26:1086-1093

9. Gokce N, Keaney JF Jr, Hunter LM et al (2003) Predictive value of noninvasively determined endothelial dysfunction for longterm cardiovascular events in patients with peripheral vascular disease. J Am Coll Cardiol 41:1769-1775

10. Kimoto E, Shoji T, Shinohara K et al (2003) Preferential stiffening of central over peripheral arteries in type 2 diabetes. Diabetes 52:448-452

11. Oliver JJ, Webb DJ (2003) Noninvasive assessment of arterial stiffness and risk of atherosclerotic events. Arterioscler Thromb Vasc Biol 23:554-566

12. van Venrooij FV, van de Ree MA, Bots ML, Stolk RP, Huisman MV, Banga JD (2002) Aggressive lipid lowering does not improve endothelial function in type 2 diabetes: the Diabetes Atorvastatin Lipid Intervention (DALI) Study: a randomized, double-blind, placebo-controlled trial. Diabetes Care 25:1211-1216

13. Waring WS, Webb DJ, Maxwell SR (2000) Uric acid as a risk factor for cardiovascular disease. QJM 93:707-713

14. Perry IJ, Wannamethee SG, Walker MK, Thomson AG, Whincup PH, Shaper AG (1995) Prospective study of risk factors for development of non-insulin dependent diabetes in middle aged British men. BMJ 310:560-564

15. Rathmann W, Hauner H, Dannehl K, Gries FA (1993) Association of elevated serum uric acid with coronary heart disease in diabetes mellitus. Diabetes Metab 19:159-166

16. Fang J, Alderman MH (2000) Serum uric acid and cardiovascular mortality the NHANES I epidemiologic follow-up study, 19711992. National Health and Nutrition Examination Survey. J Am Med Assoc 283:2404-2410

17. Lehto S, Niskanen L, Ronnemaa T, Laakso M (1998) Serum uric acid is a strong predictor of stroke in patients with non-insulindependent diabetes mellitus. Stroke 29:635-639

18. Seghieri G, Moruzzo D, Fascetti S et al (2002) Increase in serum uric acid is selectively associated with stroke in type 2 diabetes. Diabetes Care 25:1095

19. Kato M, Hisatome I, Tomikura Y et al (2005) Status of endothelial dependent vasodilation in patients with hyperuricemia. Am J Cardiol 96:1576-1578

20. Butler R, Morris AD, Belch JJ, Hill A, Struthers AD (2000) Allopurinol normalizes endothelial dysfunction in type 2 diabetics with mild hypertension. Hypertension 35:746-751

21. Mercuro G, Vitale C, Cerquetani E (2004) Effect of hyperuricemia upon endothelial function in patients at increased cardiovascular risk. Am J Cardiol 94:932-935

22. Corry DB, Tuck ML (2006) Uric acid and the vasculature. Curr Hypertens Rep 8:116-119

23. Berry CE, Hare JM (2004) Xanthine oxidoreductase and cardiovascular disease: molecular mechanisms and pathophysiological implications. J Physiol 555:589-606 
24. Khosla UM, Zharikov S, Finch JL et al (2005) Hyperuricemia induces endothelial dysfunction. Kidney Int 67:1739-1742

25. Kang DH, Park SK, Lee IK, Johnson RJ (2005) Uric acid-induced C-reactive protein expression: Implication on cell proliferation and nitric oxide production of human vascular cell. J Am Soc Nephrol 16:3553-3562

26. Leyva F, Anker SD, Godsland IF et al (1998) Uric acid in chronic heart failure: A marker of chronic inflammation. Eur Heart J 19:1814-1822

27. Zoccali C, Maio R, Mallamaci F, Sesti G, Perticone F (2006) Uric acid and endothelial dysfunction in essential hypertension. J Am Soc Nephrol 17:1466-1471

28. Feig DI, Mazzali M, Kang DH et al (2006) Serum uric acid: a risk factor and a target for treatment? J Am Soc Nephrol 17(Suppl 2): S69-S73

29. The Expert Committee on the Diagnosis and Classification of Diabetes Mellitus (1997) Report of the Expert Committee on the Diagnosis and Classification of Diabetes Mellitus. Diabetes Care 20:1183-1197

30. Benjamin N, Calver A, Collier J, Robinson B, Vallance P, Webb D (1995) Measuring forearm blood flow and interpreting the responses to drugs and mediators. Hypertension 25:918-923

31. Deanfield J, Donald A, Ferri C et al (2005) Endothelial function and dysfunction. Part I: methodological issues for assessment in the different vascular beds: a statement by the Working Group on Endothelin and Endothelial Factors of the European Society of Hypertension. J Hypertens 23:7-17

32. Takazawa K, O'Rourke MF, Fujita M et al (1996) Estimation of ascending aortic pressure from radial arterial pressure using a generalised transfer function. Z Kardiol 85(Suppl 3):137-139

33. Wilkinson IB, Fuchs SA, Jansen IM et al (1998) Reproducibility of pulse wave velocity and augmentation index measured by pulse wave analysis. J Hypertens 16:2079-2084

34. Pauca AL, O'Rourke MF, Kon ND (2001) Prospective evaluation of a method for estimating ascending aortic pressure from the radial artery pressure waveform. Hypertension 38:932-937

35. O'Brien E, Mee F, Atkins N, Thomas M (1996) Evaluation of three devices for self-measurement of blood pressure according to the revised British Hypertension Society Protocol: the Omron HEM-705CP, Philips HP5332, and Nissei DS-175. Blood Press Monit 1:55-61

36. Oldfield V, Perry CM (2006) Rasburicase: a review of its use in the management of anticancer therapy-induced hyperuricaemia. Drugs 66:529-545

37. Mahmoud HH, Leverger G, Patte C, Harvey E, Lascombes F (1998) Advances in the management of malignancy-associated hyperuricaemia. Br J Cancer 77(Suppl 4):18-20
38. Doehner W, Schoene N, Rauchhaus M et al (2002) Effects of xanthine oxidase inhibition with allopurinol on endothelial function and peripheral blood flow in hyperuricemic patients with chronic heart failure: results from 2 placebo-controlled studies. Circulation 105:2619-2624

39. George J, Carr E, Davies J, Belch JJ, Struthers A (2006) Highdose allopurinol improves endothelial function by profoundly reducing vascular oxidative stress and not by lowering uric acid. Circulation 114:2508-2516

40. Kuppusamy UR, Indran M, Rokiah P (2005) Glycaemic control in relation to xanthine oxidase and antioxidant indices in Malaysian Type 2 diabetes patients. Diabet Med 22:1343-1346

41. Kelley EE, Trostchansky A, Rubbo H, Freeman BA, Radi R, Tarpey MM (2004) Binding of xanthine oxidase to glycosaminoglycans limits inhibition by oxypurinol. J Biol Chem 279:3723137234

42. Lyons D (1997) Impairment and restoration of nitric oxidedependent vasodilation in cardiovascular disease. Int J Cardiol 62 (Suppl 2):S101-S109

43. Leach M, Parsons RM, Reilly JT, Winfield DA (1998) Efficacy of urate oxidase (uricozyme) in tumour lysis induced urate nephropathy. Clin Lab Haematol 20:169-172

44. Waring WS, Maxwell SR, Webb DJ (2002) Uric acid concentrations and the mechanisms of cardiovascular disease. Eur Heart $\mathrm{J}$ 23:1888-1889

45. Radi R, Tan S, Prodanov E, Evans RA, Parks DA (1992) Inhibition of xanthine oxidase by uric acid and its influence on superoxide radical production. Biochim Biophys Acta 1122:178-182

46. Tan S, Radi R, Gaudier F et al (1993) Physiologic levels of uric acid inhibit xanthine oxidase in human plasma. Pediatr Res 34:303-307

47. Guthikonda S, Sinkey C, Barenz T, Haynes WG (2003) Xanthine oxidase inhibition reverses endothelial dysfunction in heavy smokers. Circulation 107:416-421

48. Koh KK, Quon MJ, Han SH et al (2004) Additive beneficial effects of losartan combined with simvastatin in the treatment of hypercholesterolemic, hypertensive patients. Circulation 110:3687-3692

49. Ceriello A, Assaloni R, Da Ros R et al (2005) Effect of atorvastatin and irbesartan, alone and in combination, on postprandial endothelial dysfunction, oxidative stress, and inflammation in type 2 diabetic patients. Circulation 111:2518-2524

50. Kim SH, Park KW, Kim YS et al (2003) Effects of acute hyperglycemia on endothelium-dependent vasodilation in patients with diabetes mellitus or impaired glucose metabolism. Endothelium 10:65-70 